\title{
Preterm children quality of life evaluation: a qualitative study to approach physicians' perception
}

Marie-Ange Einaudi ${ }^{1,2^{*}}$, Marie-Claude Simeoni ${ }^{3}$, Catherine Gire ${ }^{1}$, Pierre Le $\mathrm{Coz}^{2}$, Sophie Condopoulos ${ }^{4}$ and Pascal Auquier ${ }^{3}$

\begin{abstract}
Background: While data for preterm children health-related quality of life are available, there are little data on the perception of health-related quality of life evaluation by physicians who manage preterm children, or its use in real life and decision making. The aim of this qualitative study is to highlight among physicians, themes of reflection about health-related quality of life in extremely preterm children (less than 28 weeks' gestation).

Methods: Focus groups at a French University Hospital with physicians who manage extremely preterm children: obstetricians, intensive care physicians, neonatal physicians and paediatric neurologists. The focus groups allowed the participants to discuss (drawing on their personal experience), three principal topics regarding the health-related quality of life of preterm children: representation, expectations in daily practice and evaluation method.

Results: We included fourteen participants in the three focus groups. Many themes emerged from the focus groups: approaches for defining health-related quality of life and difficulties of utilization, the role that health-related quality of life should have in the system of care, the problem of standards and evidence-based decision making. Physicians had difficulties with taking positions regarding this concept. There were no differences by gender, age or seniority, but points of view varied by specialty and type of practice. Physicians who had longer specialized care for extremely preterm children were more sensitive to the impact of preterm complications on health-related quality of life.

Conclusions: This study provides preliminary results about physicians' perspective on the health-related quality of life of extremely preterm children. The themes emerged from the focus groups are classically described in other domains but not all in so clear a way (definition, interests and limits, ethical reflection). This approach was never developed in the field of prematurity with well-knowed consequences on quality of life. These results require to be confirmed on a larger representative sample. The themes and questions of this broad opinion survey will rest on the information issued from our preliminary interviews.
\end{abstract}

Keywords: Qualitative study, Focus group, Preterm children, Quality of life, Physicians' perception, Ethical issues

\footnotetext{
* Correspondence: marieange.einaudi@ap-hm.fr

${ }^{1}$ Department of Neonatology, APHM, North University Hospital, Marseille,

France

Espace Ethique Méditerranéen, Aix-Marseille Univ, UMR 7268 -

Anthropologie bio-culturelle, Droit, Éthique \& Santé (ADÉS), APHM, Timone

University Hospital, Marseille, France

Full list of author information is available at the end of the article
} 


\section{Background}

The consequences for extremely preterm children (EPC) ( $<28$ weeks' gestation) are well known in terms of mortality and morbidity [1,2]. Interest is increasing in not only these traditional health indicators but also in the subjective representation of health and well-being, also known as health-related quality of life (HRQoL); the subjective evaluation of quality of life (QoL) is possibly as important for the patient as the traditional focus on morbidity and the prolongation of life [3,4]. HRQoL evaluation seems important because complications affect the daily basis of formerly EPC during early school age [5-7]. However, even if data on HRQoL for formerly EPC are available, they are limited because age groups are limited; indeed, if consequences on HRQoL seem more marked at early preschool age [8] than at the teenager [9] or the young adult $[10,11]$, this report can be biased because of the mode of evaluation of the QoL which varies with the age of the subject and according to the methodology $[3,4]$.

In chronic diseases, the perceptions of physicians of the HRQoL of their patients often differ from those of the patients and their families [8,12-14]. While HRQoL data are available, there are little data on the basic understanding and perception of quality of life issues by perinatologist physicians as well as the day-to-day experience of the patient or the role it plays in clinical decision-making [15-17]. The need for quality data in this area is all the more important as these physicians are directly involved in the decisions taken with regard to neonatal resuscitation (even if these decisions take into account the families' opinions) as well giving us a more stable platform for relaunching the public debate. What is the impact of the neonatal resuscitation in term of quality of life?

It would be relevant to highlight the opinions of perinatology experts regarding EPC HRQoL, and in particular physicians because they are the decision-makers. We report in a preliminary qualitative study the first step of the project. The aim was to produce themes of reflection and identify subjects that would imply study on a larger scale.

\section{Methods}

Eligible participants were experts who manage EPC at the French University Hospital of Marseille, composed of four hospitals. Two of them are involved in the care of very preterm children (level 3 maternities), one in the long term follow up of the children; another hospital is involved in the long term follow up. The participants were defined as follows: more than 18 years old; both genders; having a minimal level of resident practice; involved in the care of the EPC (obstetricians, intensive care physicians, neonatal physicians, psychologists and paediatric neurologists); having agreed to participate in the study; registered on the list of the staff working in the University Hospital. The participants were selected by drawing lots stratified by the main clinical functions from the list. They were asked to complete a short sociodemographic and clinical characteristics questionnaire.

We used the qualitative method of focus groups (FGs) to generate data using the opinions collectively expressed by the participants [18-20], as it has been used in other contexts and more specifically with children [21].

Focus groups were designed to include at least one representative from each specialty. Confounding factors such as age, gender, function and practice were also considered; according to the hospitals, preterm children can be cared in departments of neonatal intensive care units where neonatologists work, and in mixed paediatric and neonatal intensive care departments (newborns and older children) where intensive care physicians work. The FG were organized according to the availability of the participants. A minimum of two FGs was planned, but the number was increased until a saturation of information was reached beyond which no new concepts were emerging from the FGs. Five new participants would be selected from new drawing lots.

Focus groups were audio-recorded and moderated by a well trained social psychologist (SC) using a discussion guide with guidelines and open-ended questions. The guide was based on an analysis of the literature and centred on the prioritised themes to be discussed: HRQoL representation, expectations in daily practice, HRQoL evaluation (i.e. Table 1). The psychologist supplemented the prepared questions with sub-questions that enabled the researchers to explore participants' answers in greater detail. She encouraged equal participation from the whole group and encouraged people to engage with one another to create a dynamic discussion that would characterize the specificity of group conversations rather than individual interviews.

All the sessions were manually content-analysed by the social psychologist. The data were coded and classified by reviewing the transcribed discussions for categories, using the guideline questions as initial categories. Data relevant to the research questions were identified. Within categories, the different items were written up as statements. Relevant statements that did not fit into the predefined categories were assigned to new categories $[19,20,22,23]$. A second independent review of the data codes and categories was made by a physician (MAE). At the end, the coherence of this content analysis was confirmed by an external expert from the Self Perceived Health Assessment Research Unit (MCS). Opinions were compared between the participants' characteristics (gender, age, experience, specialty and practice-type). 
Table 1 Discussion guide

\begin{tabular}{|c|c|c|c|}
\hline Main themes & Sub- themes & Associated questions & Questions of relaunching \\
\hline \multirow[t]{9}{*}{ HRQoL* representation } & Perception & $\begin{array}{l}\text { What does the HRQoL concept } \\
\text { evoke for each of you? }\end{array}$ & $\begin{array}{l}\text { What do you think about HRQoL and well-being } \\
\text { measurements? }\end{array}$ \\
\hline & & $\begin{array}{l}\text { How do you perceive this } \\
\text { notion? }\end{array}$ & How would you define HRQoL as a concept? \\
\hline & & & What do you consider the important dimensions? \\
\hline & & & What is the time of relevance of such a concept? \\
\hline & Knowledge & $\begin{array}{l}\text { What knowledge do you have } \\
\text { of its application in the field } \\
\text { of health? }\end{array}$ & Do you know of tools for the evaluation of HRQoL? \\
\hline & & & Do you think they are relevant? Which one? Why? \\
\hline & Experience & $\begin{array}{l}\text { What experience do you have } \\
\text { with it in your practice? }\end{array}$ & Have you ever participated in a study of HRQoL? \\
\hline & & & $\begin{array}{l}\text { Have you already used a HRQoL questionnaire in your } \\
\text { practice? Why? How? }\end{array}$ \\
\hline & & & Do you assess the HRQoL of your patients? How? Why? \\
\hline \multirow{4}{*}{$\begin{array}{l}\text { Expectations in daily practice } \\
\text { of such a concept in } \\
\text { extremely preterm children }\end{array}$} & Interests & $\begin{array}{l}\text { What is your interest in the } \\
\text { HRQoL concept? }\end{array}$ & What is the utility of its evaluation in your specific practice? \\
\hline & & & $\begin{array}{l}\text { What are the interests of the medical community towards } \\
\text { such data? }\end{array}$ \\
\hline & & & $\begin{array}{l}\text { How could HRQoL evaluation change the way your practice } \\
\text { for your patients? }\end{array}$ \\
\hline & Limitations & $\begin{array}{l}\text { What are the limitations of } \\
\text { this concept and its evaluation? }\end{array}$ & $\begin{array}{l}\text { Do you think that a standardised evaluation could } \\
\text { potentially damage your intuitive evaluation of the } \\
\text { well-being of your patients? }\end{array}$ \\
\hline \multirow[t]{7}{*}{ HRQoL evaluation } & $\begin{array}{l}\text { HRQoL evaluation in } \\
\text { daily practice }\end{array}$ & $\begin{array}{l}\text { Do you think every patient } \\
\text { should be evaluated? }\end{array}$ & $\begin{array}{l}\text { How could HRQOL assessment become a tool integrated } \\
\text { into the care of preterm children in your daily practice? }\end{array}$ \\
\hline & & $\begin{array}{l}\text { How could you use HRQoL } \\
\text { evaluation in daily practice? }\end{array}$ & \\
\hline & & $\begin{array}{l}\text { When do you think it would } \\
\text { be important to make this } \\
\text { evaluation? }\end{array}$ & $\begin{array}{l}\text { What effects and consequences could its evaluation } \\
\text { have in your relationship with your patients? }\end{array}$ \\
\hline & & Who should assess HRQoL? & What would you make of a "bad" HRQoL evaluation? \\
\hline & $\begin{array}{l}\text { Questions } \\
\text { about the tool }\end{array}$ & $\begin{array}{l}\text { What would be an ideal } \\
\text { questionnaire? }\end{array}$ & What do you think of the existing questionnaires? \\
\hline & & & $\begin{array}{l}\text { How would you envision a standardized evaluation: number } \\
\text { of questions, duration, kind of notation? }\end{array}$ \\
\hline & & & What are the important dimensions of HRQoL to estimate? \\
\hline
\end{tabular}

*HRQoL: Health-related quality of life.

All participants provided informed consent. Anonymity and confidentiality of information were guaranteed. Ethical approval was obtained from French legal authority: the National Committee of Computing and Liberties.

\section{Results}

\section{FG characteristics}

Fifteen participants were contacted and 14 participated. The characteristics of participants are reported in Table 2. Two FGs were initially conducted; in the second, new information emerged with regard to the first FG, so we conducted a third FG during which saturation of information was obtained.

\section{Content analysis}

According to all the participants, the concept of HRQoL encompasses several aspects of life and is influenced by the environment in which we live (evaluation necessarily contextual: social, cultural, economical...). It is as a complex concept that can be limited to a consequence of one's health. Although the definition of HRQoL was not clear according to the participants, a consensus emerged about the impact of health on various aspects of life, with particular importance assigned to family, social and school contexts. Parental evaluation of the HRQoL of children was deemed necessary ("Parents are the main judges of their children's lives") as assessment 
Table 2 Demographic data and clinical characteristics

\begin{tabular}{|c|c|c|c|c|}
\hline Focus groups population & $\mathrm{N}=14$ & $\begin{array}{l}\text { First Focus group } \\
\mathrm{N}=4\end{array}$ & $\begin{array}{l}\text { Second Focus group } \\
\mathrm{N}=6\end{array}$ & $\begin{array}{l}\text { Third Focus group } \\
\mathrm{N}=4\end{array}$ \\
\hline Age (years) & $36.3(24-62)$ & $25.5(24-27)$ & $41(28-62)$ & $40.2(31-53)$ \\
\hline Female gender & $10(71.4 \%)$ & $4(100 \%)$ & $3(50 \%)$ & $3(75 \%)$ \\
\hline $\begin{array}{l}\text { Experience with extremely } \\
\text { preterm children (years) }\end{array}$ & $7.8(1-36)$ & $2(1-4)$ & $11.8(3-36)$ & $7.5(2-10)$ \\
\hline \multicolumn{5}{|l|}{ Function: } \\
\hline Senior physicians & $8(57.1 \%)$ & 0 & $4(66.7 \%)$ & $4(100 \%)$ \\
\hline Junior physicians & $5(35.7 \%)$ & $4(100 \%)$ & $1(16.7 \%)$ & 0 \\
\hline Psychologist & $1(7.2 \%)$ & 0 & $1(16.7 \%)$ & 0 \\
\hline \multicolumn{5}{|l|}{ Specialties: } \\
\hline Obstetricians & $2(14.3 \%)$ & 0 & $1(16.7 \%)$ & $1(25 \%)$ \\
\hline Neonatal physicians & $7(50 \%)$ & $4(100 \%)$ & $1(16.7 \%)$ & $2(50 \%)$ \\
\hline Intensive care physicians & $2(14.3 \%)$ & 0 & $2(33.3 \%)$ & 0 \\
\hline Paediatric neurologists & $2(14.3 \%)$ & 0 & $1(16.7 \%)$ & $1(25 \%)$ \\
\hline Psychologist & $1(7.1 \%)$ & 0 & $1(16.7 \%)$ & 0 \\
\hline \multicolumn{5}{|c|}{ Type of practice with very preterm children*: } \\
\hline Perinatal period only & $2(14.3 \%)$ & 0 & $1(16.7 \%)$ & $1(25 \%)$ \\
\hline Perinatal period + short-term care & $8(57.2 \%)$ & $4(100 \%)$ & $3(50 \%)$ & $1(25 \%)$ \\
\hline $\begin{array}{l}\text { Perinatal + short-term care }+ \\
\text { long-term follow-up }\end{array}$ & $3(21.4 \%)$ & 0 & $2(33.3 \%)$ & $1(25 \%)$ \\
\hline Long-term follow-up only & $1(7.1 \%)$ & 0 & 0 & $1(25 \%)$ \\
\hline Duration of the Focus groups (minutes) & $100(60-120)$ & 60 & 120 & 120 \\
\hline
\end{tabular}

*Type of practice with extremely preterm children: "short-term care" = during hospitalisation; "long-term follow-up"= consultations for follow-up for more than 4 years with neurocognitive screening after 4 years.

of the HRQoL of parents ("The QoL of a child can be good even if the QoL of his or her parents is not"). This finding does not exclude the value of caregivers' assessments ("It is interesting to evaluate each person's perception [parents, child, caregivers] to confront his/her opinions"). Because perceptions are inherently subjective, they can vary significantly; a neonatologist asked if a perception could be more valid than the other one and in which perception to trust. ("What is the truth?").

Participants were confronted with the difficulty of HRQoL subjective and changing nature (i.e., that it is an adaptive process that changes as priorities change) (An intensive care physician said:"Patients with a handicap can have a good QoL at one time and a bad QoL at another period in their lives, but it is the same thing for everybody, with or without handicaps; it depends on children's psychological evolution, their social integration, the consciousness that they have of their difficulties, their family situation...").

One limitation reported by the participants was related to the interpretation of the quantitative values derived from the questionnaires, that asked the meanings of norms. Moreover, the FGs revealed an interest in conducting assessments measuring different dimensions of
HRQoL ("We can imagine that a child who has a walking disorder is not satisfied because he cannot play for sports with his friends but at the same time, is able to play music, which would be better for him").

Health-related quality of life seems to be a potential informational tool: along with other factors within the framework of prematurity, HRQoL adds an additional dimension to evaluations of the EPC, especially when parents ask for concrete information about the future of their child (A neonatologist said: "Parents want to know what they are waiting for with their child: How will they plan his/her school or educational life? Could he/she make friends? Could he/she play sports or engage in cultural activities? What relationships will he/she have with others? What will the duration of the disease be? How frequently will hospitalizations occur?"). According to some neonatologists and the two paediatric neurologists, health-related quality of life evaluation could improve communication among families, children and caregivers, helping families anticipate problems and understand why and in what situations HRQoL can decline.

Knowledge about HRQoL studies and about the tools used to measure HRQoL was not precise, even when participants (particularly neonatologists) said that the 
QoL concept was sometimes used among "ethical thinking staff" in perinatal units, when they have to discuss withdrawing therapy.

There were no differences by gender, age or seniority, but perspectives varied by specialty and type of practice. Physicians who cared for EPC only during the perinatal period (i,e., obstetricians and intensive care physicians) said they did not take HRQoL into account. According to them, this notion is too subjective, depending of many factors and too evolutive to be taken into account. The application of this notion in the emergency perinatal contexts cannot be supposed. Conversely, physicians who provided long-term follow-up care for EPC (i,e., neonatal physicians and paediatric neurologists) indicated that considering HRQoL was essential, at the same time to improve the relation of care and the information. The paragraphs below illustrate this.

The vision of the HRQoL concept was slightly inconsistent with the themes discussed among the neonatal physicians. In reflecting on HRQoL, some were certain of its value for improving care and providing information. Others were more reserved, noting that HRQoL changes both over time and between patients ("Responses to illness are highly individual, with difficulty in generalising QoL data"), thus limiting its utilization. Some neonatal physicians explained their hesitation and their difficulty in establishing standards for QoL, which cannot be generalizable. Quality of life could suggest a reflection of "life" and the notion of "quality":"What is a good life?" with the "idea of a judgement that would depend on the society in which we live".

Paediatric neurologists and neonatal physicians involved in long-term follow-up were conversely more aware of HRQoL methodology. They were more sensitive to the impact of prematurity on HRQoL both because they followed families more closely and because they were aware of the burden of care and the psychological, social and economic consequences. (A neonatologist said: "To estimate the HRQoL of our patients, it is to estimate the echo of the pathology in their daily life." A paediatric neurologist added: "It can influence the care, by estimating for example the burden of the reeducations".)

Consideration of long-term outcomes was irrelevant to professionals involved in acute perinatal care (An obstetrician said: "How can I justify the delivery of an extremely preterm infant in the context of an emergency if the data say that QoL could be bad? The immediate stakes in certain urgent perinatal situations outweigh the long-term potential QoL in children...It is impossible to talk to parents about data such as QoL because it is a question of managing situations with stakes in short-term survival, not of risking failure in the future."). HRQoL seemed to appear "dangerous" to some participants (An obstetrician said: "it is not enough to estimate QoL: it is necessary to know what we are going to do with this evaluation...Can it influence medical decisions, knowing that this concept is evolutionary? In prenatal staff, using QoL data could favour termination of pregnancy requests."). Because they provide care focused on patient survival rather than long-term qualitative outcomes, intensive care physicians believe that HRQoL could not represent a decision-making argument in terms of neonatal resuscitation, raising the issue of the "sacredness of life" versus the "QoL". (An intensive care physician said: "When a very preterm child is born, the immediate stake is not its long-term quality of life, but mostly its survival".)

\section{Discussion}

In this preliminary study, focus groups made appear themes of reflection classically told about HRQoL in other domains but not all in so clear a way (definition, interests and limits, ethical reflection) [13,14,24,25].

All the themes discussed hold considerable interest for the participants. These themes touched many dimensions: QoL as both a theoretical and practical issue, the physicians' practical experience, that of the value as well as the limits to this type of approach. However, three sub-themes seemed particularly relevant to the group.

The first one of them concerns the definition of the quality of life.

The FGs' participants seemed to have embraced the definition of HRQoL given by Eiser and Morse, identifying some key elements such as "subjectivity and multidimensional aspects" [26]. Although they recognized a subjective aspect, the participants indicated that a parental approach was necessary. This pragmatic attitude is in accordance with several studies in which parental evaluation was realized, especially with children less than six years old $[5,6,8,27]$.

The second sub-theme concerns the limits of the use of quality of life concepts.

One of the limitations identified by users is that it seems difficult that the construct underlying the QoL is not constant at all ages of life of children and adolescents. The adaptive process relative to these specific periods of life are multiple referring indifferently to complex process of redefinition but also of recalibration of response or reprioritization of domains. The nature of HRQoL must be renegotiated throughout life [28]. Therefore, it seems illusory to imagine that what structures the QoL of each individual is invariable. For the participants, this evolution would prevent any standardized HRQoL evaluation. Because a child is continuously maturing, developing and changing, then the whole concept of HRQoL is invalid anyway. 
Why would this "evolutionary" factor be a limitation for subjective measurement and not for objective measurement? One obstacle to using QoL measurement seems to be related to the implicit comparison with a standard or norm (perhaps because of a misunderstanding about the tools of measurement). Obviously, this subject is often reported on by experts who argue for the subjectivity of the measure used. However, in the field of so-called "non-objective" measures, many indicators are used to assess consensual aspects, such as intelligence quotient. Additionally, one might similarly question the value of several of our so-called objective measures, such as neurocognitive assessments, behaviour disorders, children' size... The standards of certain objective criteria are not without problems. This issue raises the problem of the definition of the standard and its utilization. Canguilhem discussed the individualization of the standard in his criticism of the positivist determination of the normal and the pathological [29]. The "pathological" becomes an experience lived before being measured. Mistrust towards the objectivity of standards is, henceforth, a common problem in contemporary ethical culture. Using HRQoL standards does not mean defining a "normal life" but improving the everyday life of patients according to their situations $[30,31]$.

Finally, the third sub-theme concerns decision-making with respect to QoL.

The main question addressed in the FGs was whether HRQoL assessments can assist in evidencebased decision-making. HRQoL seems to have a limited impact on perinatal guidelines. Globally, HRQoL is almost exclusively used as secondary criterion $[17,32,33]$. What would be the limit of this criterion if HRQoL data were available? There are many paradoxes. Participants said they were not familiar with HRQoL tools, but they knew the different aspects of the debate surrounding the topic with real practice attitudes. The differences in the evocation of QoL concept among "ethical thinking staffs" in perinatal units for withdrawing therapy (a way of clearing themselves of responsibility by taking into account at least one time what people could feel?), the lack of knowledge concerning evaluation methods and the fears expressed in the FGs do not position HRQoL as a criterion for making decisions in perinatal situations.

There were several limitations to our study. Participants were selected from one geographic region, and their experiences and opinions may not be generalizable. It is recognized in FG research that the recruited sample is not representative of the entire population but is rather a snapshot of those people participating in the study [34]. The presence of dominant participants and opinion leaders could have been a confounding factor; the experienced social psychologist controlled this issue.
Some of the differences in perspectives that have appeared to be conflicts of opinions, can be explained by the varying professional and social positions of the participants. The sample size of the FGs should be discussed: to optimize group discussion, the size of the groups must be limited to avoid the creation of sub groups; at the same time, the groups must be large enough to allow for the emergence of a variety of controversial themes. The sample size and the limited number of FGs could appear as a limitation but saturation of information was nevertheless reached. Most authors support that adequate size of each group is between four and twelve individuals and the use of a minimum of three FGs with each type of participant; sufficient FGs have been conducted when no new information emerges from the dialogue of subsequent groups [34-36]. Focus Groups' composition was not homogeneous because they were organized according to the availability of the participants. The heterogeneity of the participants allowed for the expression of different opinions about the subject. Paediatrician neurologists were included with perinatalology experts because they have experience in specialized EPC follow-up care. The participants were mostly female but it is a representation of the French medical reality and especially the profession of paediatrician, as it is described in the French review of social fields by Lapeyre and Le Feuvre [Unpublished observation: "Feminization of the medical profession and professional dynamics in the field of the health" Revue française des affaires sociales, 2005, 1: 59-81] and in the report of the National Center of health professions' demography [37].

Focus groups are used to explore topics on which little research has been conducted and have the advantage of enabling researchers to quickly identify the full range of perspectives held by participants [35]. Moreover, the interactional nature of FGs allows participants to clarify or expand on their contributions during the discussion in light of the points raised by the other participants.

\section{Conclusions}

Our original, qualitative study provides preliminary results about physicians' perspective on the healthrelated quality of life of extremely preterm children. This approach was never developed in the field of prematurity with well-knowed consequences on QoL. These results require to be confirmed on a larger representative sample including leaders of obstetrics, neonatal medicine, neonatal intensive care units of French University Hospitals as well french paediatrician neurologists. The themes and questions of this broad opinion survey will rest on the information issued from our preliminary interviews. 


\section{Abbreviations}

EPC: Extremely preterm children; HRQoL: Health-related quality of life; QoL: Quality of life; FG: Focus group; SC: Sophie Condopoulos; MAE: MarieAnge Einaudi; MCS: Marie-Claude Simeoni.

\section{Competing interests}

The authors declare that they have no competing interests.

\section{Authors' contributions}

MCS, PA and MAE participated in the conception and design of the study. SC and MAE analyzed the data. PA and MAE participated in the drafting of the article. All the authors contributed to a critical revision of the manuscript and made a substantial contribution to its content, and read and approved the final manuscript.

\section{Acknowledgements}

We are very grateful to the participants who agreed to share their perspectives and experiences. We are particularly grateful to the University Hospital Direction Research Units, which allowed the realisation of the study, which was supported by the Allowance Organisation for Clinical Research We thank the reviewers of the review HQLO of which comments allowed to improve the quality of this work.

\section{Author details}

${ }^{1}$ Department of Neonatology, APHM, North University Hospital, Marseille, France. ${ }^{2}$ Espace Ethique Méditerranéen, Aix-Marseille Univ, UMR 7268 Anthropologie bio-culturelle, Droit, Éthique \& Santé (ADÉS), APHM, Timone University Hospital, Marseille, France. ${ }^{3}$ EA 3279 « Self Perceived Health Assessment Research Unit », Aix-Marseille Univ, Marseille, France. ${ }^{4}$ Social Psychologist, CAMSP La Rose, Marseille, France.

Received: 8 June 2012 Accepted: 26 September 2012

Published: 28 September 2012

\section{References}

1. Larroque B, Ancel PY, Marret S, Marchand L, André M, Arnaud C, Pierrat V, Rozé JC, Messer J, Thiriez G, Burguet A, Picaud JC, Bréart G, Kaminski M, EPIPAGE Study group: Neurodevelopmental disabilities and special care of 5-year-old children born before 33 weeks of gestation (the EPIPAGE study): a longitudinal cohort study. Lancet 2008, 371:813-820.

2. Brevaut-Malaty V, Busuttil M, Einaudi MA, Monnier AS, D'Ercole C, Gire C: Longitudinal follow-up of a cohort of 350 singleton infants born at less than 32 weeks of amenorrhea: neurocognitive screening, academic outcome, and perinatal factors. Eur J Obstet Gynecol Reprod Biol 2010 150(1):13-18.

3. Saigal S, Tyson J: Measurement of quality of life of survivors of neonatal intensive care: critique and implication. Semin Perinatol 2008, 32:59-66.

4. Zwicker JG, Harris SR: Quality of life of formerly preterm and very low birth weight infants from preschool age to adulthood: a systematic review. Pediatrics 2008, 121(2):e366-e376.

5. Stahlmann N, Rapp M, Herting E, Thyen U: Outcome of extremely premature infants at early school age: health-related quality of life and neurosensory, cognitive and behavioral outcomes in a population-based sample in Northern Germany. Neuropediatrics 2009, 40(3):112-119.

6. Vederhus BJ, Markestad T, Eide GE, Graue M, Halvorsen T: Health related quality of life after extremely preterm birth: a matched controlled cohort study. Health Qual Life Outcomes 2010, 8(1):53.

7. Berbis J, Einaudi MA, Simeoni MC, Brévaut-Malaty V, Auquier P, D'Ercole C, Gire C: Quality of life of early school-age French children born preterm: A cohort study. Eur J Obstet Gynecol Reprod Biol 2012, 162(1):38-44.

8. Theunissen NC, Veen S, Fekkes M, Koopman HM, Zwinderman KA, Brugman E, Wit JM: Quality of life in preschool children born preterm. Dev Med Child Neurol 2001, 43(7):460-465.

9. Gray R, Petrou S, Hockley C, Gardner F: Self-reported health status and health-related quality of life of teenagers who were born before 29 weeks' gestational age. Pediatrics 2007, 120(1):e86-e93.

10. Saigal S, Stoskopf B, Pinelli J, Streiner D, Hoult L, Paneth N, Goddeeris J: Self-perceived health-related quality of life of former extremely low birth weight infants at young adulthood. Pediatrics 2006, 118(3):1140-1148.
11. Baumgardt M, Bucher HU, Mieth RA, Fauchère JC: Health-related quality of life of former very preterm infants in adulthood. Acta Paediatr 2012, 101(2):e59-e63.

12. Janse AJ, Sinnema G, Uiterwaal CSPM, Kimpen JLL, Gemke RJBJ: Quality of life in chronic illness: perceptions of parents and paediatricians. Arch Dis Child 2005, 90:486-491

13. Janse AJ, Gemke RJBJ, Uiterwaal CSPM, van der Tweel I, Kimpen JL, Sinnema G: Quality of life: patients and doctors don't always agree: a metaanalysis. J Clinic Epid. 2004, 57:653-661.

14. Marino BS, Tomlinson RS, Drotar D, Claybon ES, Aguirre A, Ittenbach R, Welkom JS, Helfaer MA, Wernovsky G, Shea JA: Quality of life concerns differ among patients, parents, and medical providers in children and adolescants with congenital and acquired heart disease. Pediatrics 2009, 123:e708-e715.

15. Carr AJ, Gibson B, Robinson PG: Measuring quality of life: Is quality of life determined by expectations or experience? BMJ 2001, 322(7296):1240-1243.

16. Addington-Hall J, Kalra L: Who should measure quality of life? BMJ 2001, 322(7299):1417-1420.

17. Efficace F, Bottomley A: Do quality-of-life randomized clinical trials support clinicians in their decision-making? J Clin Oncol 2002, 20(19):4126-4127.

18. Morgan DL, Krueger R, King JA: The focus group guidebooks. vol 1-6. London: Sage Publications Inc; 1998.

19. Kitzinger J: Qualitative research. Introducing focus groups. BMJ 1995 311:299-302.

20. Powell RA, Single HM: Focus Groups. Int J Qual Health Care 1996, 8(5):499-504.

21. Detmar SB, Bruil J, Ravens-Sieberer U, Gosch A, Bisegger C, European KIDSCREEN group: The use of focus groups in the development of the KIDSCREEN HRQL questionnaire. Qual Life Res 2006, 15(8):1345-1353.

22. Grisez J: Methodes de psychologie sociale. Paris: Presses Universitaires de France; 1975. Le psychologue

23. Bardin L: L'analyse de contenu. Paris: Presses Universitaires de France, DL; 2007.

24. Barlési F, Tchouhadjian C, Doddoli C, Astoul P, Thomas P, Auquier P: Quality of life: attitudes and perspectives of doctors in a thoracic oncology regional care network. Sante Publique 2006, 18(3):429-442.

25. Kvam AK, Fayers P, Hjermstad M, Gulbrandsen N, Wisloff F: Health-related quality of life assessment in randomised controlled trials in multiple myeloma: a critical review of methodology and impact on treatment recommendations. Eur J Haematol 2009, 83(4):279-289.

26. Eiser $C$, Morse R: The measurement of quality of life in children: past and future perspectives. J Dev Behav Pediatr 2001, 22(4):248-256.

27. Rautava L, Häkkinen U, Korvenranta E, Andersson S, Gissler M, Hallman M, Korvenranta H, Leipälä J, Linna M, Peltola M, Tammela O, Lehtonen L: Health-related quality of life in 5-year-old very low birth weight infants. J Pediatr 2009, 155(3):338-343.

28. Marra CA, Levine M, McKerrow R, Carleton BC: Overview of health-related quality-of-life measures for pediatric patients: application in the assessment of pharmacotherapeutic and pharmacoeconomic outcomes. Pharmacotherapy 1996, 16(5):879-888.

29. Canguilhem G: Le normal et le pathologique. 11th edn. Paris: Presses Universitaires de France; 2009.

30. Van der Velde JL, Flokstra-de Blok BM, Dunngalvin A, Hourihane JO, Duiverman EJ, Dubois AE: Parents report better health-related quality of life for their food-allergic children than children themselves. Clin Exp Allergy 2011, 41(10):1431-1439.

31. Calman KC: Quality of life in cancer patients-an hypothesis. J Med Ethics 1984, 10(3):124-127.

32. Woodrow P: Measuring quality of life. J Med Ethics 2001, 27(3):205

33. Levine MN, Ganz PA: Beyond the development of quality-of-life instruments: where do we go from here? J Clin Oncol 2002, 20(9):2215-2216

34. Halcomb EJ, Gholizadeh L, DiGiacomo M, Phillips J, Davidson PM: Literature review: considerations in undertaking focus group research with culturally and linguistically diverse groups. J Clin Nurs 2007, 16(6):1000-1011.

35. Kroll T, Barbour R, Harris J: Using focus groups in disability research. Qual Health Res 2007, 17(5):690-698. 
36. Krueger RA, Casey MA: Focus Groups: a practical guide for applied research. 3rd edn. Thousand Oaks, CA: Sage Publications Inc; 2000.

37. Observatoire national de la démographie des professions de santé: Les effectifs et l'activité des professionnels de santé. Tome I. Paris: La

Documentation française; 2004. www.ladocumentationfrancaise.fr/ rapports-publics/.../index.shtml.

doi:10.1186/1477-7525-10-122

Cite this article as: Einaudi et al:: Preterm children quality of life evaluation: a qualitative study to approach physicians' perception. Health and Quality of Life Outcomes 2012 10:122.

\section{Submit your next manuscript to BioMed Central} and take full advantage of:

- Convenient online submission

- Thorough peer review

- No space constraints or color figure charges

- Immediate publication on acceptance

- Inclusion in PubMed, CAS, Scopus and Google Scholar

- Research which is freely available for redistribution 